\title{
ALTERNATIVAS DE PROCEDIMENTOS ESTATÍSTICOS PARA AVALIAÇÃO DE GENÓTIPOS EM PROGRAMAS DE MELHORAMENTO GENÉTICO VEGETAL
}

\author{
MARIA CRISTINA DUARTE RIOS \\ Engenheiro Agrônomo
}

Orientador: PROF. DR. DÉCIO BARBIN

Dissertação apresentada à Escola Superior de Agricultura "Luiz de Queiroz", Universidade de São Paulo, para obtenção do título de Mestre em Agronomia, Área de Concentração Estatística e Experimentação Agronômica

PIRACICABA

Estado de São Paulo - Brasil

Julho - 1997 
Dados Internacionais de Catalogação na Publicação (CIP) DIVISÃo DE BIBLIOTECA E DOCUMENTAÇÃO - Campus "Luiz de Queiroz"/USP

Rios, Maria Cristina Duarte

Alternativas de procedimentos estatísticos para avaliação de genótipos em programas de melhoramento genético vegetal / Maria Cristina Duarte Rios. - Piracicaba, 1997.

$59 \mathrm{p}$.

Dissertação (mestrado) - - Escola Superior de Agricultura Luiz de Queiroz, 1997. Bibliografia.

1. Delineamento de experimento 2. Estatística agricola 3. Genética vegetal 4. Genótipo vegetal 5. Melhoramento genético vegetal 6 . Método estatistico I. Titulo.

CDD 631.522 


\title{
ALTERNATIVAS DE PROCEDIMENTOS ESTATÍSTICOS PARA AVALIAÇÃO DE GENÓTIPOS EM PROGRAMAS DE MELHORAMENTO GENÉTICO VEGETAL
}

\author{
MARIA CRISTINA DUARTE RIOS
}

Aprovada em: 12.09.1997

Comissão julgadora:

Prof. Dr. Décio Barbin

Prof $^{\mathrm{a}} \operatorname{Dr}^{\mathrm{a}}$ Maria Cristina Stolf Nogueira

Prof. Dr. Antonio Carlos de Oliveira
ESALQ / USP

ESALQ / USP

EMBRAPA / CNPMS

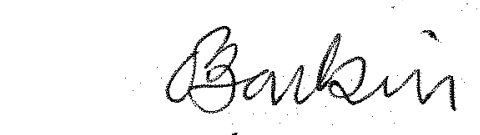

Prof. Dr DÉCIO BARBIN

Orientador 
Aos meus pais, João Márcio e Nilda

Ao Irving

Dedico.

Não só pelo apoio e compreensão mas, principalmente pelo amor que a mim dedicam. 


\section{AGRADECIMENTOS}

À Escola Superior de Agricultura "Luiz de Queiroz", pela oportunidade concedida.

Ao programa PICDT/CAPES da Universidade Federal de Lavras pela concessão da bolsa.

Ao Prof. Dr. Décio Barbin pela amizade, ensinamentos e orientação prestados durante todo o curso.

Ao Departamento de Ciências Exatas da Universidade Federal de Lavras pelo apoio e compreensão.

Ao Programa de Melhoramento do Feijoeiro do Departamento de Biologia da Universidade Federal de Lavras, por ter concedido dados para o desenvolvimento desse trabalho.

Ao Pesquisador da EMBRAPA/CNPMS Dr. Antônio Carlos de Oliveira, pela disponibilidade e sugestões dadas.

Aos Professores da Curso de Pós-Graduação em Estatística e Experimentação Agronômica da Escola Superior de Agricultura "Luiz de Queiroz", pelos ensinamentos transmitidos. 
Aos funcionários do Departamento de Matemática e Estatística da Escola Superior de Agricultura “Luiz de Queiroz", pelo apoio e dedicação.

À Alexandra, Cristiane e Roselane, não só pela amizade, mas também por toda a dedicação e apoio prestados.

$\mathrm{E}$, a todas as pessoas que de uma maneira ou de outra contribuíram para o sucesso desse trabalho. 


\section{SUMÁRIO}

RESUMO

vii.

SUMARY

ix.

1. INTRODUÇÃO

01.

2. REVISÃO DE LITERATURA

03.

2.1. Látice

03.

2.2. Delineamentos em blocos aumentados

12.

2.3. Médias móveis (vizinhos mais próximos)

17.

2.4. Testemunha Intercalar

26.

2.5. Análise de covariância

29.

2.6. Comparação entre os métodos

30.

3. MATERIAL E MÉTODOS

3.1. Blocos Incompletos - Látice 36.

3.2. Blocos Incompletos - Blocos Aumentados 37.

3.3. Blocos Casualizados 39 .

3.4. Testemunha Intercalar 40.

3.5. Método das Médias Móveis 41.

3.6. Discussão dos Métodos 42.

4. RESULTADOS E DISCUSSÃO 43. 
5. CONCLUSÕES

49.

REFERÊNCIAS BIBLIOGRÁFICAS

50. 


\title{
ALTERNATIVAS DE PROCEDIMENTOS ESTATÍSTICOS PARA AVALIAÇÃO DE GENÓTIPOS EM PROGRAMAS DE MELHORAMENTO GENÉTICO VEGETAL
}

\author{
Autora: MARIA CRISTINA DUARTE RIOS \\ Orientador: Prof. Dr. DÉCIO BARBIN
}

\section{RESUMO}

Programas de melhoramento vegetal, em sua fase inicial, caracterizam-se pela pouca disponibilidade de material para compor tamanhos de parcelas e um número de repetições consideradas ideais, além da frequente necessidade de avaliação de um grande número de progênies. Procurou-se, com este trabalho, escolher um dos procedimentos estatísticos já existentes para melhor avaliação de progênies, considerando estas limitações e, procurando afetar ao mínimo a precisão das estimativas. Para tanto, foi avaliado experimento de feijão com 121 progênies $S_{2}$, provenientes de um programa de seleção recorrente, em Lavras - MG. Utilizou-se um látice simples $11 \times 11$. Adicionalmente, foram incluídas duas testemunhas Carioca e EMGOPA 201 - Ouro, sendo que cada testemunha foi alocada a intervalos regulares de cinco em cinco parcelas por bloco. Os dados de produção de grãos (g/parcela) do feijoeiro foram submetidos à 
análises de variância considerando-se os seguintes procedimentos: látice, blocos aumentados, blocos casualizados, testemunha intercalar e método das médias móveis. Realizou-se a comparação entre os diferentes procedimentos quanto à sua eficiência no controle do erro experimental e em relação à precisão das estimativas de parâmetros genéticos em cada método. A partir dos resultados obtidos conclui-se que: o emprego do delineamento em blocos aumentados é viável para a seleção de progênies em etapas iniciais de programas de melhoramento de plantas; o delineamento em blocos aumentados não se mostrou apropriado para a estimação de parâmetros genéticos, devido à baixa precisão das estimativas; o método da médias móveis foi eficiente no controle da heterogeneidade dos blocos, sendo esta eficiência similar àquela proporcionada pela análise em látice. 


\title{
ALTERNATIVES STATISTICS PROCEDURES FOR GENOTYPE EVALUATION IN PLANT GENETIC BREEDING PROGRAMS
}

\author{
Author: MARIA CRISTINA DUARTE RIOS \\ Adviser: Prof. Dr. DÉCIO BARBIN
}

\section{SUMMARY}

Vegetable breeding programs, in their initial stage, distinguish for little avaibility of material to constitute the size of the plots and a quantity of repetitions considered ideal, besides the frequent necessity of estimate a big number of progenies. With this work, tried to choose one statistic procedures already existing, in order to estimate better the progenies, taking in mind these limitations and looking for affect, at least, the accuracy of estimations. For that was evaluated, in Lavras - MG, one experiment with 121 progenies $S_{2}$ of beans, coming from a program of a going back over selection. Were made use of a simple lattice $11 \times 11$. Besides this, were included two witness "Carioca" and "EMGOPA 201-Ouro", in such a way, that each witness were added at regular intervals of five to five plots per block. The grains production data $(\mathrm{g} / \mathrm{parcel})$ of beans, were submited to variance analysis, considering the following procedures: lattice design, augmented block design, randomized block desing, check plots 
method and moving-means method. Was done a comparison among the different procedures in relation to their efficiency in controlling the experimental error and in relation to the accuracy over the evaluation of genetics parameters in each method. From the results gotten, its possible to conclude: using designs in augmented block desing is practicable in case of selection of progenies in initiating programs of plants breeding; the design in augmented blocks, however, was not appropriated for the estimation of genetic parameters, because of the reduced accuracy of the estimates; moving-means method was efficient in the control of the heterogenity of the block, and this efficiency similar to that provided for analysis in lattice desing. 


\section{INTRODUÇÃO}

Programas de melhoramento vegetal, em sua maioria, iniciam-se com seleção massal, obtendo-se daí sementes de várias hibridações diferentes. Nesses programas, o pesquisador estuda um número elevado de genótipos e, devido a heterogeneidade ambiental, adota-se o delineamento em blocos casualizados. Porém, apesar desse delineamento amenizar o problema da heterogeneidade, ele pode não ser eficiente nesse controle da heterogeneidade devido ao grande número de parcelas. Com tudo isso, o pesquisador opta por outros tipos de delineamentos, dentre eles: látice e blocos aumentados com as metodologias de médias móveis e testemunha intercalar.

Tradicionalmente, os pesquisadores da área de melhoramento de plantas utilizam, amplamente, o delineamento em látice, que permite a avaliação de um grande número de tratamentos sem, com isso, comprometer a precisão dos resultados. Entretanto, outro procedimento que elimine a necessidade de repetições seria desejável, tanto pela economia de área experimental, como pela pequena disponibilidade de material nas fases iniciais de um programa de melhoramento genético vegetal. Portanto, outras metodologias propostas constituem-se em alternativas de grande interesse, como os delineamentos aumentados de Federer (1956) ou o ajuste para efeitos ambientais, como o uso de médias móveis e o de testemunha intercalar. 
A utilização de um delineamento estatístico adequado às características e limitações de um programa de melhoramento de plantas é um dos fatores essenciais para a obtenção de estimativas o mais eficientes possível. Tal escolha deve seguir alguns critérios, como: a determinação das estimativas, sendo os testes de hipótese de interesse prático e os intervalos de confiança de magnitudes aceitáveis; a segurança, através de baixas probabilidades dos erros tipo I e II.

Este trabalho tem por objetivo comparar metodologias estatísticas nos programas de melhoramento de plantas, visando à eficiência, precisão das estimativas envolvidas e sua viabilidade. Estas metodologias são os delineamentos em blocos completos casualizados, látices, blocos aumentados, o ajuste de valores fenotípicos a partir de médias móveis e as testemunhas intercalares. 


\section{REVISÃO DE LITERATURA}

$\mathrm{Na}$ experimentação agrícola, o pesquisador tem como objetivo comparar diferentes tratamentos com a maior precisão possível, levando-se também em conta a viabilidade do delineamento escolhido para sua avaliação e estimação de parâmetros.

Chaves (1985) cita que a precisão do experimento está intimamente relacionada ao erro experimental, sendo esta uma medida da variação não controlada ou aleatória que ocorre no experimento. Cita, também, que existem vários fatores que podem afetar a precisão experimental, entre eles, a heterogeneidade do solo, do material genético e os cuidados na condução do experimento.

\subsection{Látice}

Os delineamentos chamados reticulados quadrados ou látices quadrados, foram propostos por Yates (1936) como uma alternativa para a avaliação de um grande número de tratamentos, situação comum nos programas de melhoramento de plantas. $\mathrm{O}$ autor cita que este delineamento foi criado com o 
objetivo de eliminar a heterogeneidade dentro dos blocos. Este tipo de delineamento foi criado como uma estrutura pseudo-fatorial com dois fatores cada qual com $\mathrm{p}$ níveis, totalizando $\mathrm{p}^{2}$ tratamentos dispostos em blocos de $\mathrm{p}$ parcelas. A estimação dos pseudo-efeitos dos níveis dos fatores e de suas interações fornece a base para se estimar o efeito dos tratamentos. A dimensão cúbica $\left(\mathrm{p}^{3}\right)$ também foi sugerida.

Federer (1955) mantém a abordagem de uma estrutura pseudofatorial e apresenta estimadores para vários tipos de látice. Os delineamentos em látice são, na realidade casos particulares de delineamentos em blocos incompletos, onde os blocos contêm apenas uma fração do total de tratamentos. Esses delineamentos são ditos balanceados (BIB) quando todos os pares de tratamentos ocorrem juntos num mesmo bloco em mesmo número de vezes (Cochran e Cox, 1966). Os pseudo-efeitos de todas as interações não se confundem com diferenças entre blocos incompletos (Federer, 1955). Os delineamentos BIB foram apresentados por Yates (1936). Neste tipo de delineamento, por haver blocos incompletos, os fatores blocos e tratamentos não são ortogonais entre si, e, por isso os estimadores dos efeitos de tratamento apresentam ajuste para bloco e vice-versa. Portanto, a soma de quadrados de parâmetros do modelo matemático pode ser decomposta sequencialmente de maneira que a soma de quadrados de blocos é ajustada para a média somente, e a de tratamentos para a média e para blocos. Esta análise é chamada intrablocos, devido à variação entre tratamentos ser estimada somente a partir de comparações entre parcelas de mesmo bloco (Riboldi, 1988). Yates (1939) demonstrou que o contraste entre totais de blocos continha efeitos de tratamentos, que poderiam ser utilizados para melhorar as estimativas obtidas no método de análise intrablocos. Este procedimento foi chamado de recuperação da informação interblocos. 
Federer (1955) cita que quando essa recuperação é efetuada, a variância residual pode ser no máximo ligeiramente superior àquela estimada em uma análise de um delineamento em blocos casualizados nas mesmas condições, e, se não realizada, a variância residual da análise intrablocos pode ser muito maior.

A condição de balanceamento pode inviabilizar certos experimentos por exigir um número excessivo de repetições. Assim, Bose e Nair (1939) propuseram os delineamentos em blocos incompletos parcialmente balanceados (PBIB), onde o número de vezes que dois tratamentos aparecem juntos no mesmo bloco varia para diferentes pares de tratamentos. Esse número de vezes é comumente simbolizado por $\lambda$. Se, para o conjunto de pares de tratamentos, existem dois valores de $\lambda$, o delineamento é dito ter duas classes de associados, e assim sucessivamente. Se existe somente uma classe de associados, o delineamento é evidentemente balanceado.

No planejamento de delineamentos em látice parcialmente balanceados, a disposição dos tratamentos nos blocos deve variar de tal forma que diferentes pares de tratamentos ocorram nas diferentes repetições, de maneira que os efeitos das diferenças entre tratamentos estejam confundidos ao mínimo com os efeitos de blocos incompletos. Quando se varia esta disposição, diz-se que estão sendo usados arranjos básicos diferentes, e repetições com diferentes arranjos básicos são ortogonais entre si, como visto em Pimentel Gomes (1987).

De acordo com Federer (1955), os látices são classificados em: 
a) bi-dimensionais com $\mathrm{k}^{2}$ tratamentos (látices quadrados ou reticulados quadrados)

a.1) controle local em apenas uma direção.

Este tipo de látice possui $\mathrm{k}$ blocos de $\mathrm{k}$ parcelas, em cada repetição. Esta classificação se subdivide de acordo com o número de arranjos básicos. Eles se tornam balanceados se contiverem todos os tipos possíveis de arranjos básicos. Pimentel Gomes (1987) observa que para um látice com $\mathrm{k}^{2}$ tratamentos, é possível dispor um máximo de $\mathrm{k}+1$ repetições ortogonais, ou seja, $\mathrm{k}+1$ arranjos básicos, sendo que para certos números de tratamentos isso não é possível, por exemplo, para 36 e 100 tratamentos. Isso é o mesmo que dizer que para tais números de tratamentos não é possível estruturar látices balanceados.

a.2) controle local em duas direções.

São também chamados de quadrados reticulados. Por repetição, possuem $\mathrm{k}$ linhas e $\mathrm{k}$ colunas ambas, é claro, incompletas, totalizando os $\mathrm{k}^{2}$ tratamentos. Podem ser não - balanceados, semi - balanceados e balanceados.

b) bi-dimensionais com $\mathrm{p}$ blocos de $\mathrm{k}$ parcelas por repetição (látices retangulares).

$\mathrm{O}$ autor considera esse caso geral de p.k tratamentos, porém os látices retangulares mais utilizados têm sido os de $\mathrm{k}(\mathrm{k}+1)$ tratamentos, propostos por Harshbarger (1949).

b.1) controle local em uma direção.

O controle local é feito através de $\mathrm{p}$ blocos por repetição.

b.2) controle local em duas direções.

O controle local é feito através de $\mathrm{p}$ linhas e $\mathrm{k}$ colunas.

c) tri-dimensionais com $\mathrm{k}^{3}$ tratamentos ( látices cúbicos).

Utilizados quando é necessário avaliar números muito grandes de tratamentos. 


\section{c.1) controle local em uma direção}

Cada repetição tem que conter $\mathrm{k}^{2}$ blocos de $\mathrm{k}$ parcelas cada.

c.2) controle local em duas direções

Através do uso de $\mathrm{k}^{2}$ linhas e $\mathrm{k}$ colunas, incompletas.

c.3) controle local em mais de duas direções

Por exemplo, formando k reticulados quadrados por repetição.

Federer (1955) também apresenta látices de dimensões superiores a essas, com diversas possibilidades quanto ao número de arranjos básicos empregados. Nos programas de melhoramento genético vegetal, em geral, utilizam-se os látices parcialmente balanceados.

Mesmo a classificação de Federer (1955), sendo a mais abrangente, outras classificações mais simplificadas têm sido utilizadas, como a de Cochran \& Cox (1966), que classifica os látices quanto ao seu balanceamento e número de repetições.

O modelo estatístico geral para látices é dado por:

$$
y_{i j k}=\mu+r_{i}+b_{(i) j}+t_{k}+e_{i j k}
$$

onde:

$\mathrm{y}_{\mathrm{ijk}}:$ com $\mathrm{i}=1, \ldots, \mathrm{r}, \mathrm{j}=1, \ldots, \mathrm{b}$ e $\mathrm{k}=1, \ldots, \mathrm{t}$ é o valor observado na parcela experimental que recebeu o tratamento $\mathrm{k}$ no bloco $\mathrm{j}$ na repetição $\mathrm{i}$;

$\mu$ : é uma constante;

$\mathrm{r}_{\mathrm{i}}$ : efeito da repetição $\mathrm{i}$;

$\mathrm{b}_{(\mathrm{i}) \mathrm{j}}$ : é o efeito do bloco $\mathrm{j}$ dentro da repetição i; 
$\mathrm{t}_{\mathrm{k}}$ : é o efeito do tratamento $\mathrm{k}$;

$\mathrm{e}_{\mathrm{j} \mathrm{j} k}$ : é o efeito do erro experimental da parcela que recebeu o tratamento $\mathrm{k}$, no bloco j da repetição i. Admite-se que $\mathrm{e}_{\mathrm{ijk}} \cap \operatorname{NID}\left(0, \sigma^{2}\right)$

O efeito de bloco, é considerado como fixo, devido à necessidade de simplificação das expressões como a variância da média de tratamentos, por exemplo. Quando se faz a recuperação da informação interblocos, o efeito de blocos é considerado aleatório.

O esquema geral da análise de variância intrablocos para o delineamento em látice está apresentado na Tabela 1.

Tabela 1. Esquema geral da análise de variância intrablocos para o delineamento em látice.

\begin{tabular}{ll}
\hline Causas de Variação & Graus de Liberdade \\
\hline Repetição & $(\mathrm{r}-1)$ \\
Bloco d. Repetição & $(\mathrm{b}-1) \mathrm{r}$ \\
Tratamento (ajustado) & $(\mathrm{t}-1)$ \\
Erro & $(\mathrm{rt}-\mathrm{rb}-\mathrm{t}+1)$ \\
\hline Total & $(\mathrm{rt}-1)$ \\
\hline
\end{tabular}

onde: $r$ : número de repetições; b: número de blocos por repetição; t: número de tratamentos.

Segundo Cochran \& Cox (1966), o contraste entre médias de tratamentos que ocorrem em um mesmo bloco é estimado com uma precisão diferente daquela do contraste entre médias de tratamentos de blocos diferentes. 
Porém, a não ser em casos de experimentos pequenos, recomenda-se o uso de uma variância média para o contraste de quaisquer médias de tratamentos. É comum, como observa Miranda Filho (1987), conduzir a análise de variância do látice como se fosse um delineamento em blocos completos, considerando as repetições como blocos e considerar a variância residual de tal análise como o erro efetivo. A razão entre as duas dá a chamada eficiência do látice e, se ela se encontra na faixa de 100 a $110 \%$, diz o autor, a análise como látice não se justifica.

As expressões dos estimadores das somas de quadrados de tratamentos intra e interblocos, do erro efetivo e médias ajustadas de tratamentos podem ser encontradas, por exemplo, em Pimentel Gomes (1987).

No melhoramento de plantas, é comum os efeitos de tratamento constituírem uma variável aleatória. Assim, uma aplicação importante da análise de variância é a estimação dos componentes de variância, que permitem obter estimativas de parâmetros genéticos de interesse, como os coeficientes de herdabilidade. Métodos disponíveis de estimação de componentes de variância são vários, entre eles o método dos momentos, da máxima verossimilhança e máxima verossimilhança restrita.(Basso, 1981). O método tradicionalmente empregado é o método dos momentos, ou método da análise de variância, que consiste em igualar as esperanças dos quadrados médios às suas estimativas. Os outros métodos ganham importância especialmente em estruturas nãobalanceadas, onde as estimativas sob diferentes métodos tornam-se, em geral, não coincidentes, e as esperanças das somas de quadrados são complicadas, frequentemente não disponíveis e, mais de um tipo de soma de quadrados poderia ser empregado (Searle, 1987). No caso de análise de látices com recuperação de 
informação interblocos, as médias de tratamentos já ajustadas na análise intrablocos, sofrem um novo ajuste. A nova soma de quadrados para tratamentos ajustada pode ser calculada a partir dessas novas médias ajustadas (Pimentel Gomes, 1987). Esse procedimento, aliado ao uso do erro efetivo, faz com que a esperança do quadrado médio de tratamentos torne-se simples, semelhante a de um delineamento em blocos completos casualizados, ou seja:

$$
\mathrm{E}(\mathrm{QM} \text { Trat. Aj. })=\sigma^{2}+\mathrm{r} \sigma_{\mathrm{T}}^{2}
$$

onde $\sigma^{2}$ corresponde à variância do erro efetivo, $\sigma_{\mathrm{T}}^{2}$ à variância entre tratamentos e r o número de repetições. A simplicidade da expressão acima torna o método dos momentos particularmente interessante no caso de látices.

Outra situação comum no melhoramento de plantas é a avaliação dos genótipos em vários ambientes e/ou vários anos. Para realizar a análise conjunta desses experimentos no caso de látices, Miranda Filho (1987), bem como Cecon (1992), observam que basta trabalhar com médias ajustadas dos tratamentos, e realizar a análise como se os experimentos individuais fossem no delineamento em blocos casualizados completos, tomando-se por resíduo a média da variância dos erros efetivos, ponderados por seus respectivos graus de liberdade.

É difícil quantificar o impacto que o uso de látices teve no melhoramento de plantas ou mesmo na experimentação agrícola em geral, mas com certeza foi grande, principalmente no melhoramento do milho. Não muitos anos depois de proposto esse delineamento, Cochran, citado por Johnson \& Murphy (1943), relatou que o uso frequente de látices na Estação Experimental 
Agrícola de Iowa para avaliação de produção em ensaios com milho, levou a uma eficiência de 114 a $365 \%$ para látices e de 98 a $462 \%$ para reticulados quadrados, tomando-se como base o delineamento em blocos casualizados completos. Os resultados evidenciaram que um látice triplo seria tão eficiente quanto um delineamento em blocos completos com 5 repetições. Em relação a esse mesmo delineamento, Zuber (1942) encontrou uma eficiência média de 136\%, trabalhando com vários tipos de látice. Johnson \& Murphy (1943), trabalhando com dados de ensaio de uniformidade com aveia, simularam látices de diversos tamanhos, encontrando eficiências variando de 155 a $224 \%$. Cochran \& Cox (1966) citam outras referências que em média demonstram que delineamentos em blocos incompletos com 4 repetições seriam tão eficientes quanto delineamentos com 5 blocos completos. Resultados não tão promissores foram encontrados por Lessman \& Atkins (1963), que também simularam látices de vários tamanhos e números de repetições a partir de um ensaio de uniformidade com um híbrido de sorgo e concluem que, embora tenham sido observados ganhos relativos e até expressivos em áreas experimentais mais desuniformes, eles foram, em geral, baixos.

Schultz \& Cockerham (1966) utilizaram um critério mais diretamente ligado ao melhoramento de plantas, o ganho com a seleção. Trabalhando com estimadores do ganho e simulando diferentes tipos de heterogeneidade de solo, demonstraram como o ganho com a seleção diminui, ignorando-se o controle local, ao se aumentar a correlação entre as parcelas de um mesmo bloco. Além de evidenciarem a necessidade de controle local, seus resultados mostram que sob várias condições o tamanho do bloco deveria conter menos parcelas que o número de tratamentos, justificando a necessidade de blocos incompletos. 
Townley-Smith \& Hurt (1973) e Rosielle (1980) comparam a eficiência do látice não somente em relação ao delineamento em blocos casualizados completos, mas também em relação a outras metodologias, como a do vizinho mais próximo e a do uso de testemunha intercalar.

\subsection{Delineamentos em blocos aumentados}

Como alternativa para a avaliação de um grande número de tratamentos e um menor dispêndio de recursos nos programas de melhoramento de cana-de-açúcar, Federer (1956) adaptou delineamentos tradicionais (inteiramente casualizados, blocos completos, quadrado latino, etc.) contendo tratamentos adicionais não repetidos; daí surgiu a denominação de "aumentados". A idéia básica deste delineamento é incluir testemunhas, que são tratamentos para os quais exista material suficiente e repetir essas testemunhas diversas vezes em um delineamento padrão. Os tratamentos que aparecem com repetições são chamados de "comuns" e aqueles não repetidos são chamados de "regulares". Por esse esquema, um número elevado de tratamentos poderia ser analisado sem repetições, o que, se por um lado aumenta o erro padrão de suas médias, por outro possibilita a avaliação de um número muito maior de tratamentos em relação aos delineamentos convencionais.

Federer (1956) apresenta expressões para realização de análise de variância de delineamentos com controle local somente em uma direção, incluindo blocos completos e incompletos. Por outro lado, Federer et al (1957) estenderam a análise para casos em mais de uma direção. Federer \& Raghavarao 
(1957) apresentam expressões para se estimarem variâncias de diferenças entre médias de tratamentos em alguns delineamentos aumentados, com controle local tanto em uma como em duas direções.

Do mesmo modo que para o caso de blocos incompletos, as estimativas dos efeitos de tratamentos são ajustadas para blocos e blocos ajustados para tratamentos.

Nogueira (1976) apresentou esquemas de análise conjunta de experimentos conduzidos em vários ambientes, quando tratamentos e ambientes são ortogonais entre si. Uma situação que seria de grande interesse é a obtenção de expressões para efeitos de tratamentos e somas de quadrados para casos onde tratamentos e ambientes não são ortogonais, ou seja, nem todos os tratamentos ocorrem nos vários locais, situação esta muito comum no melhoramento de plantas, que acontece devido a perda de determinados tratamentos ou pela seleção proposital negativa de certos materiais muito inadequados. Nesta situação, as médias de tratamentos deveriam ser ajustadas não só para os blocos de cada local, mas, também, para os locais. Porém a obtenção dessas estimativas é extremamente complicada. Kshirsagar (1983) apresenta mecanismos de obtenção de expressões para efeitos de tratamentos em modelos desbalanceados com dois fatores e com interação, para a situação apresentada acima.

Lin \& Poushinsky (1983), propuseram um delineamento aumentado modificado, com o objetivo de melhorar a eficiência da avaliação de linhas em fases iniciais de um programa de melhoramento, dispondo as linhas controle, ou tratamentos comuns, de maneira sistemática nas linhas e colunas, ao invés de aleatorizadas como propôs Federer (1956). Por esse esquema as linhas a serem 
testadas (tratamentos regulares) devem ser alocadas ao redor das linhas controle em número de oito, num esquema de parcelas subdivididas. Desta forma buscouse maximizar o ajustamento dos efeitos das linhas testadas, retirando, ao máximo, os efeitos ambientais dos valores fenotípicos. Este delineamento foi testado por Schaalje et al (1987) em um programa de melhoramento de batata, que observaram uma boa redução na variância residual através do ajustamento para linhas e colunas, afetando significativamente a classificação dos materiais.

A derivação de estimadores para efeitos dos parâmetros do modelo quase sempre é apresentada através do método dos mínimos quadrados. As expressões podem variar de acordo com as restrições empregadas, mesmo sabendo que isso não afeta a estimativa das somas de quadrados, que independem das restrições empregadas para se tornar determinado o sistema de equações normais (Searle, 1987).

Federer (1956) apresenta expressões de estimadores para efeitos dos parâmetros do modelo de um delineamento em blocos completos aumentados com as seguintes características:

1. existem c tratamentos comuns que aparecem em todos os blocos e um determinado número de tratamentos regulares, não repetidos, distribuídos ao longo de todos os blocos;

2. cada tratamento comum pode aparecer mais de uma vez dentro dos blocos, sendo que o número de repetições dentro dos blocos para um dado tratamento comum é constante em todos os blocos;

3. não há restrições quanto ao tamanho dos blocos, que pode variar ao longo do experimento. 
A característica 3 faz com que o modelo seja bastante flexível, pois a análise não é afetada pela perda de tratamentos regulares, além de fazer com que o número de tratamentos regulares não seja rígido, como no caso dos látices. A característica 2 , pode ser muito útil quando se deseja a melhoria da precisão do experimento aumentando-se os graus de liberdade do resíduo. Pode-se também, ao invés de aumentar o número de repetições de um tratamento comum dentro de cada bloco, aumentar o número de blocos.

O modelo estatístico para este delineamento é:

$$
y_{i j}=\mu+t_{i}+t_{(j) i}+b_{j}+e_{i j}
$$

onde:

$y_{i j}:$ com $i^{\prime}=1, \ldots, c, i=1, \ldots k_{j-p}$ e $j=1, \ldots, b$ é o valor observado no bloco j e na parcela que recebeu o tratamento comum i' ou o tratamento regular $i$; $\mu$ : é uma constante;

$\mathrm{t}_{\mathrm{i}}$ : : é o efeito do tratamento comum i';

$t_{(j) \mathrm{i}}$ : é o efeito do tratamento regular i dentro do bloco j;

$b_{\mathrm{j}}$ : é o efeito do bloco $\mathrm{j}$;

$\mathrm{e}_{\mathrm{ij}}$ : é o efeito do erro experimental. Admite-se eij $\cap \operatorname{NID}\left(0, \sigma^{2}\right)$

$\mathrm{kj}$ : número de parcelas do bloco $\mathrm{j}$ :

$\mathrm{p}$ : é o número de parcelas em cada bloco, que contém tratamentos comuns.

$$
p=\sum_{i=1}^{c} n_{i}
$$

Precisa ser ressaltado que a parcela $\mathrm{y}_{\mathrm{ij}}$ não está recebendo os efeitos do tratamento comum $t_{i}$ e do tratamento regular $t_{(j) \mathrm{i}}$ simultaneamente; notações 
diferentes foram adotadas somente com o intuito de diferenciá-los. $\mathrm{O}$ índice i', sempre que utilizado, estará referindo-se a um tratamento comum. Outro aspecto é que será necessária a utilização de um terceiro índice para discriminar as repetições dos tratamentos comuns dentro dos blocos, mas cuja omissão nesse momento não acarretará problemas.

O esquema geral para análise de variância de um delineamento em blocos aumentados está apresentado na Tabela 2.

Tabela 2. Esquema de análise de variância de um delineamento em blocos aumentados

Causas de Variação Graus de Liberdade

Bloco

Tratamento

Resíduo

Total $[\mathrm{c}+\mathrm{b}(\mathrm{p}-\mathrm{c})-1]$

$\neq$

$(\mathrm{n}-1)$

onde: $\mathrm{b}$ é o número de blocos; $\mathrm{c}$ é o número de tratamentos comuns; $\mathrm{n}$ é o número total de parcelas; $\mathrm{p}$ é o número de parcelas por bloco que contém tratamentos comuns.

Henderson (1953) propôs três métodos de estimação de componentes de variância que correspondem à variação do método dos momentos. O terceiro método apresentado pelo autor, é o mais geral, podendo ser aplicado a modelos mistos com ou sem interação entre os parâmetros fixos com aleatórios. Outros métodos de estimação procuram maximizar a verossimilhança das observações, assumindo que os dados seguem uma distribuição normal 
multivariada, como é o caso da máxima verossimilhança e máxima verossimilhança restrita (Searle, 1987).

De modo geral, esses métodos buscam estimativas que sejam as mais prováveis de terem ocorrido, trabalhando com a distribuição de probabilidade das observações. Os estimadores de variância por máxima verossimilhança são tendenciosos, uma vez que não são corrigidos para os efeitos fixos, enquanto que a máxima verossimilhança restrita elimina essa tendenciosidade (Searle, 1987). A grande vantagem desses métodos é que sempre fornecem estimativas não negativas de componentes de variância e uma das desvantagens, é que exigem recursos computacionais de alto nível. Gonçalves (1984) trabalhou com vários métodos de estimação de componentes de variância em blocos aumentados a partir de dados simulados e dados reais e concluiu que de fato os três métodos de Henderson foram inferiores aos demais quando a variância genética é superior à ambiental e, para um grande número de observações nas mesmas condições, o método da máxima verossimilhança foi o melhor.

\subsection{Médias móveis (vizinhos mais próximos)}

$\mathrm{O}$ ajuste de valores fenotípicos pela média de parcelas vizinhas com a intenção de se removerem ao máximo os efeitos ambientais, é bem antigo. Um dos primeiros a utilizar esta metodologia foi Richey (1924), ajustando médias de progênies de milho a partir da razão entre as médias das fileiras vizinhas; e como cada fileira possui vizinhos diferentes, denominou a técnica de "médias móveis". 
Verificou, com esta técnica, reduções no erro padrão das médias após o ajuste. Havia, na ocasião, uma procura por ajustes para correção de efeitos ambientais, através do uso de regressão.

Por algum tempo esta metodologia deixou de ser usada, devido a enorme difusão de um novo enfoque para análise estatística a partir da equipe de Rothamsted. Através de delineamentos baseados em controle local, afastou um pouco essa tendência inicial, pois passou-se a considerar que parcelas sob um controle local eficiente não apresentariam observações correlacionadas, o que seria garantido pela aleatorização. Alguns anos mais tarde, Papadakis, citado por Bartlet (1938), propôs a reutilização de médias móveis, e discute este método detalhadamente. Prende-se ao uso de uma análise de covariância para o delineamento em blocos ao acaso, utilizando por covariável, para cada parcela, a média das parcelas vizinhas, subtraindo-se os efeitos dos tratamentos que as mesmas receberam. Busca-se com isso um ajuste baseado na correlação ambiental entre parcelas próximas.

Fischer (1982) cita que talvez independentemente de sua utilização na experimentação agrícola, a técnica de médias móveis está presente desde o começo do século como um dos tópicos da teoria de séries temporais, que tem por objetivo o estudo de ciclos econômicos. De acordo com esse autor a metodologia era empregada no sentido de remover componentes sazonais de um fenômeno econômico, com base em médias móveis de dimensões correspondentes ao período de um ciclo de sazonalidade, obtendo estimativas corrigidas para essas tendências sazonais. Uma teoria veio então sendo elaborada para o estudo de séries de tempo. 
Dessa forma, pode-se definir uma série estatística como toda e qualquer coleção de dados pertencentes a uma mesma classificação quantitativa, ou como uma sucessão de números referidos a qualquer variável (Toledo \& Ovalle, 1985). Quando se constrói um modelo probabilístico para descrever uma sequência de observações, diz-se estar considerando-a como um processo estocástico (Fischer 1982). Tome-se, por exemplo a série de observações:

$$
\mathrm{x}_{1}, \mathrm{x}_{2}, \ldots, \mathrm{x}_{\mathrm{n}}
$$

Se considerada como um processo estocástico, ou seja, como uma função de uma distribuição de probabilidade, diz-se que o processo é estacionário se a distribuição for a mesma para:

$$
\mathrm{x}_{1+\mathrm{h}}, \mathrm{x}_{2+\mathrm{h}}, \ldots, \mathrm{x}_{\mathrm{n}+\mathrm{h}}
$$

para todos os elementos da série e para todo h (Hannan, 1975). Isso equivale a dizer que a série não apresenta tendências ao longo dela. Classificações mais detalhadas são dadas por Fischer (1982) e este autor ainda cita que é muito importante saber se o processo é ou não estacionário, pois disso vai depender se se pode ou não considerar a série em termos de uma função amostral de uma mesma distribuição.

Uma característica interessante das séries estatísticas é que muitas vezes seus elementos podem correlacionar-se consigo mesmos e isso é denominado de auto-correlação (Toranzos, 1966). Este autor mostra que a autocorrelação surge quando uma série é comparada com ela mesma, defasada de um 
número constante de períodos. Assim, pode-se calcular um coeficiente de correlação entre os conjuntos:

$$
\text { e } \begin{gathered}
\mathrm{y}_{1}, \mathrm{y}_{2}, \ldots, \mathrm{y}_{\mathrm{n}} \\
\mathrm{y}_{1+\mathrm{s}}, \mathrm{y}_{2+\mathrm{s}}, \ldots, \mathrm{y}_{\mathrm{n}+\mathrm{s}}
\end{gathered}
$$

referentes a uma mesma série. Diz-se assim se tratar de uma auto-correlação de fase s. O processo também pode ser chamado auto-regressivo. Esta concepção pode ser prontamente extrapolada para a experimentação agrícola se houver razões para se crer que a observação de parcelas próximas é correlacionada por estarem num ambiente semelhante. Dessa maneira, parcelas próximas teriam variâncias residuais menores do que as mais distantes e esta característica é um dos alicerces de um ramo da estatística especialmente voltado para o estudo de auto-correlação no espaço, a geoestatística (Es \& Es, 1993). Da mesma forma que os conceitos da teoria de séries temporais, os conceitos da geoestatística podem ser generalizados para quaisquer outras dimensões que não o espaço.

$O$ enfoque de observações correlacionadas na experimentação agrícola ganhou um grande impulso quando Williams (1952) passou a visualizar as observações de um experimento como um processo estocástico, estacionário e propôs delineamentos com disposição de tratamentos de forma sistemática ao invés de aleatória. Atkinson (1969) procurou relacionar o método de Papadakis sob a ótica de um processo estocástico auto-regressivo, derivando estimadores e suas variâncias. 
Com o tempo, a relação entre médias móveis e autocorrelação ficou evidente. Box \& Jenkins (1976) formalizaram um modelo de médias móveis autoregressivo denominado ARMA (“Autoregressive Moving Average”). Este modelo e suas variações podem ser estendidos, inclusive, para processos nãoestacionários com o uso de um operador de transformação, formando os modelos chamados ARIMA ("Autoregressive Integrated Moving Average").

O ajuste de valores observados, segundo Yates (1936), deveria ser realizado, sempre que possível, não de forma simples, como por exemplo

$$
y_{i}^{\prime}=y_{i}-\frac{\left(y_{i-1}+y_{i+1}\right)}{2}
$$

mas através de algum parâmetro estimado, como por exemplo um coeficiente de regressão:

$$
y_{i}^{\prime}=y_{i}-b \frac{\left(y_{i-1}+y_{i+1}\right)}{2}
$$

Dessa maneira, evitar-se-ia o chamado sobreajuste dos valores, subtraindo-se um valor superior ao efeito ambiental que se pretende retirar.

Bos \& Hennink (1991) na avaliação de genótipos utilizando-se de ajuste por médias móveis, interpretam a situação da seguinte maneira: o valor fenotípico do material i em uma dada parcela pode ser decomposto e esta decomposição pode ser da seguinte forma: 


$$
p_{i}=g_{i}+E_{i}+e_{i}
$$

em que $g_{i}$ corresponde ao desvio genético do material $i, E_{i}$ é o efeito ambiental devido a fatores locais comuns as parcelas vizinhas e $e_{i}$ é o efeito ambiental relativo a fatores locais particulares de cada parcela. Os fenótipos das parcelas vizinhas correspondem a:

$$
\begin{aligned}
& p_{i-1}=g_{i-1}+E_{i-1}+e_{i-1} \\
& p_{i+1}=g_{i+1}+E_{i+1}+e_{i+1}
\end{aligned}
$$

e a média móvel correspondente ao fenótipo i será:

$$
\frac{\left(p_{i-1}+p_{i+1}\right)}{2}
$$

$$
\begin{aligned}
& \text { A expressão } \\
& E_{i}=\frac{\left(E_{i-1}+E_{i+1}\right)}{2}
\end{aligned}
$$

pode ser tida como verdadeira, independentemente de tendências que possam haver no solo. Assim, o ajuste pela média móvel removerá esse componente ambiental e o uso do coeficiente de regressão permitirá que somente ele seja removido.

Ao se utilizarem médias móveis, pode ser realizado um ajustamento com apenas um tipo de média móvel (e consequentemente um só coefíciente), por 
exemplo sempre utilizando as médias das duas parcelas vizinhas. Nesse caso, o modelo é chamado de média móvel de primeira ordem (Fischer, 1982). Se forem utilizados dois tipos de médias móveis, por exemplo a partir de duas distâncias, o modelo inclui dois parâmetros e é chamado de média móvel de segunda ordem e, assim, sucessivamente.

Bartlet (1978) apresenta o método com controle local em uma e duas direções e os estimadores indicam uma tendência crescente na eficiência ao se aumentar o número de tratamentos. $\mathrm{O}$ autor ainda cita que esse ganho pode eventualmente crescer se for utilizado um processo iterativo para estimação dos efeitos dos parâmetros do modelo.

Wilkinson et al (1983) valendo-se de estudos de simulação a partir de dados de ensaios de uniformidade, concluíram que o método de Papadakis é tendencioso, independentemente do uso ou não de interações. Sua principal crítica ao método é o fato de ter um enfoque essencialmente estacionário, o que, segundo os autores, não deve corresponder ao que ocorre nos solos, onde tendências de graduação de fertilidade e outras características devem ocorrer. Assim, propõem um novo modelo de vizinho mais próximo que prevê, simultaneamente, uma tendência suave no solo (caracterizando um processo não-estacionário) e um erro independente. Baseando-se em dados de um experimento com cevada e também simulações com ensaios de uniformidade, apontam resultados promissores para ganhos em eficiência.

Vivaldi (1990), cita que, devido à preocupação com a heterogeneidade do solo na experimentação de campo e sua influência na estimativa de diferenças entre tratamentos, (Papadakis, 1937), recomendou o uso 
de correlação entre parcelas vizinhas como uma alternativa aos blocos, método conhecido como método de Papadakis.

Kempton \& Howes (1981) registraram aumentos significativos em eficiência com o método de Papadakis (Bartlet, 1978), a partir de dados de um grande número de ensaios com trigo e cevada. Pearce (1978) também verificou reduções nos coeficientes de variação pelo uso do método em vários ensaios de milho.

A partir daí, vários outros modelos, variações e métodos de estimação têm sido publicados. Williams (1986) propôs um modelo que utiliza tanto blocos incompletos quanto o ajustamento pelos vizinhos mais próximos, utilizando o método dos quadrados mínimos generalizados. Besag \& Kempton (1986) propuseram um modelo baseado em contrastes entre parcelas vizinhas para ajustes devido a variações em fertilidade do solo. Estes e outros autores como Kempton (1982), utilizam os valores dos vizinhos mais próximos para ajustar efeitos de competição entre parcelas, ao invés de variações em fertilidade do solo. Este último autor observa que se houver uma correlação positiva entre parcelas próximas, isso é um indicativo de que ajustes são possiveis para correção das diferenças de fertilidade do solo. Por outro lado, se a correlação for negativa, isso indica efeitos de competição, onde parcelas com plantas mais desenvolvidas acarretam um prejuízo para suas vizinhas.

Juntamente com a construção de modelos, diferentes métodos de estimação têm sido propostos, como estimadores de máxima verossimilhança (Ord, 1975) e o uso do melhor preditor linear não tendencioso (Stroup \& Mulitze, 1991). 
Pearce \& Moore (1976), reuniram resultados de experimentos com espécies perenes em diferentes países e verificaram uma redução no erro padrão com o emprego do método de Papadakis, com exceção dos ensaios com macieira na Inglaterra. Esta melhoria englobou culturas diferentes como chá e videira. Lockwood (1980), trabalhando com cacau e utilizando o mesmo método, chegou a obter $20 \%$ de redução no erro padrão de diferenças entre tratamentos.

Shorter \& Butler (1986) utilizaram covariáveis a partir de médias móveis em ensaios de avaliação de progênies de amendoim em gerações avançadas, tanto removendo como não removendo efeitos de tratamento. Constataram que a análise de covariância pode diminuir tendências observadas nos resíduos, bem como a variância residual. Não houve um comportamento consistente com relação à variância genética após o ajustamento, e assim os autores apontam que a escolha da média móvel, com ou sem a retirada dos efeitos de tratamento, deve assentar-se principalmente na redução ou não da variância residual.

Weinbaum et al. (1990) encontraram um aumento em eficiência na seleção massal de porta-enxertos em nogueiras pela correção com médias móveis. Diers et al (1991), embora observando reduções no coeficiente de variação, não verificaram diferenças significativas no ganho com a seleção de cultivares de soja quanto à eficiência na absorção de Fe em solos calcáreos. 


\subsection{Testemunha intercalar}

Besag \& Kempton (1986) citam a disposição sistemática de testemunhas em ensaios de avaliação, como uma das primeiras maneiras encontradas para se controlar a variação ambiental em ensaios de melhoramento. Wiancko (1914), enfatiza a necessidade da utilização de testemunha intercalar, sugerindo inclusive sua disposição nas mesmas parcelas ao longo dos anos e utilizar essa informação acumulada de maneira a melhorar o ajuste. McClelland (1926) discute algumas alternativas disponíveis de se fazer o ajustamento em função de testemunhas.

Besag \& Kempton (1986) citam que o fato de não se dispor, em fases iniciais, de um programa de melhoramento em geral, de sementes suficientes para compor repetições com tamanhos mínimos de parcela com os materiais a serem avaliados é uma das principais razões para o uso tão generalizado quanto antigo deste método em programas de melhoramento. Assim, outras maneiras tiveram que ser buscadas para controlar a variação ambiental.

Yates (1936) relata que a princípio não há uma melhor forma de ajustamento, se subtraindo ou dividindo pela observação das testemunhas intercalares, mas aconselha a utilização de um coeficiente de regressão para se evitar o sobreajustamento. Assim, seria possível construir um índice ambiental com base na média dos valores das testemunhas intercalares, ponderada ou não por sua distância relativa, o qual construiria uma variável independente que explicaria parte do comportamento dos materiais avaliados, através de regressão linear. O coeficiente de regressão estimado seria então utilizado no ajustamento. 
Mesmo sendo métodos diferentes, testemunha intercalar e médias móveis, os mesmos possuem o mesmo fundamento, ou seja, o de que as observações de parcelas próximas são correlacionadas por estarem sujeitas a uma condição local similar.

$\mathrm{O}$ uso de testemunha intercalar tem sido criticado sob vários aspectos. Jensen \& Federer (1964) observaram que o efeito de competição de parcelas vizinhas em ensaios de trigo, devido à diferença de altura, poderia comprometer a eficácia do método. Baker \& McKenzie (1967) estudaram não só a sua eficiência, mas as consequências de se utilizar ou não o coeficiente de regressão no ajuste. Para tal, simularam vários tipos de heterogeneidade de solo, através da variação do coeficiente de heterogeneidade de Smith (1938), variando de 0,1 a 0,9 . A variância do erro esperada foi até mesmo maior do que quando não se usou nenhum ajuste, para valores acima de 0,5 para o coeficiente de Smith, sem o uso do coeficiente de regressão no ajuste. Quando este é usado, a variância do erro sempre é diminuída, porém de forma considerável apenas para valores do coeficiente abaixo de 0,5. Em dois ensaios de campo, os autores encontraram, para um ensaio, nenhuma diminuição na variação do erro, e, para o outro, uma diminuição de cerca de $14 \%$. Argumentou-se, porém, que mesmo esse ensaio seria de eficiência questionável, uma vez que cerca do dobro da área seria requerida para a inclusão das testemunhas. Baseando-se em valores de coeficiente de heterogeneidade listados por Smith (1938), Baker \& McKenzie (1967) admitem que existe uma chance em duas de se dispor de um solo cujo coeficiente seja maior que 0,5 . Recomendam, portanto, que o uso de testemunhas intercalares não deveria nunca substituir o uso de repetições. No caso de haver pouco material para a instalação do ensaio, uma análise de covariância deveria ser conduzida na área para verificar a ocorrência de reduções expressivas na estimativa do erro. 
Townley-Smith \& Hurt (1973) criticaram o uso de testemunha intercalar, citando que o método muitas vezes tem sido utilizado com um tal distanciamento entre as testemunhas, que a sua correlação com as observações das parcelas com os materiais a serem testados é praticamente nula.

Besag \& Kempton (1986), porém a partir de dados de avaliação de progênies $F_{5}$ de trigo não-repetidas, com o uso de duas testemunhas, alocadas a cada 6 parcelas, observaram que o comportamento delas é coincidente com o dos materiais avaliados ao longo da área, evidenciando sua utilidade como indicador das condições do solo. Além disso, mostram que, se as progênies fossem selecionadas tão somente com base em seu valor fenotípico, seriam selecionadas somente aquelas nas regiões de maior fertilidade, ao passo que com o uso de testemunha intercalar, as progênies selecionadas distribuem-se ao longo de todo a área. Recomendam ainda o ajuste a partir de observação de várias testemunhas, com o uso da mediana ao invés da média para contornar a desvantagem de valores discrepantes.

Godoi (1991), utilizando testemunha intercalar na avaliação de progênies de meio-irmãos em milho, embora tendo tido problemas de stand, o que comprometeu um pouco a interpretação dos resultados, concluiu que a metodologia deve ser utilizada. 


\subsection{Análise de covariância}

O emprego da análise de covariância é um procedimento que pode melhorar a precisão de ensaios em látice ou em blocos aumentados, ou qualquer delineamento, que entre outras utilidades, pode contribuir para a redução da variância residual (Cochran, 1957). Diferentes metodologias, como o uso de médias móveis e delineamentos em látice, podem ser reunidas através da análise de covariância, o que fornece a base teórica de alguns métodos, como o de Papadakis (Bartlet, 1938).

Zelen (1957) observa que as aparentes variações nas expressões para realizar uma análise de covariância em diferentes delineamentos, o fundamento é essencialmente o mesmo e, para os delineamentos em blocos incompletos, não são diferentes. Consiste basicamente em:

i. Estimar o coeficiente de regressão a partir da covariância e variância residuais, removendo os outros efeitos do modelo;

ii. Trabalhar com dois modelos, um reduzido, que não considera os efeitos dos tratamentos e outro não reduzido, levando em conta tais efeitos.

Podem-se encontrar maiores detalhes sobre esta metodologia em Steel \& Torrie (1980).

A soma de quadrados de tratamentos ajustada para regressão é obtida subtraindo-se a soma de quadrados de resíduos (ajustada) no modelo nãoreduzido daquela do modelo reduzido. Para uma análise de covariância múltipla, a 
única diferença é que os coeficientes de regressão são estimados pela resolução do sistema de equações normais (Cochran, 1957).

\subsection{Comparação entre os métodos}

Os métodos relacionados anteriormente muitas vezes têm sido comparados quanto à sua eficiência no controle ambiental. Townley-Smith \& Hurt (1973), trabalhando com trigo, estudaram a eficiência do ajuste por médias móveis e testemunha intercalar, concluindo que o primeiro foi melhor, superior inclusive à análise de covariância, usando as médias móveis como covariáveis. Mak et al (1978) compararam estes métodos e também o látice na seleção de linhagens de cevada. Obtiveram resultados que mostraram que tanto o uso de testemunha intercalar, de médias móveis, quanto a análise em látice promoveram um nível semelhante de controle de erro. No tocante a outros aspectos, os autores enumeram como vantagem dos dois primeiros métodos, a possibilidade de dispensar a necessidade de repetições e que o uso de médias móveis seria ainda mais eficiente por evitar ter de alocar cerca de $50 \%$ de área adicional como testemunhas. Por outro lado, o uso de testemunha intercalar permite que se colham apenas as parcelas de interesse.

Rosielle (1980), comparando o delineamento em látice, o uso de testemunha intercalar e o de médias móveis em ensaios de avaliação de trigo, encontrou estimativas para o coeficiente de variação e herdabilidade semelhantes para os três métodos, ligeiramente menos eficiente para médias móveis. No entanto, como $1 / 4$ da área foi destinada ao uso de testemunhas, o autor indica que 
um delineamento em blocos ao acaso com três repetições usando a média móvel como covariável é mais eficiente do que um delineamento com quatro repetições usando a testemunha intercalar como covariável.

No método proposto por Lin \& Poushinsky (1983) de um delineamento aumentado modificado, os autores comentam que sob determinadas situações o método, que se vale apenas do ajuste para controle local, (denominado, por eles, de método 1) não seria eficiente e que outros ajustamentos deveriam ser utilizados e propõem a construção de um índice de fertilidade baseado na observação dos tratamentos comuns, sem a utilização de regressão (método 2), ou com a regressão (método 3 ).

Estudos de simulação foram feitos por Lin; Poushinsky \& Jui (1983) para compará-los e observaram que em solos com variações unidirecionais, o método 1 seria o melhor, enquanto que numa tendência multidirecional, o método 3 seria o mais indicado. O método 2 é em geral menos eficiente. Os autores comparam ainda o delineamento aumentado como o látice, que se mostrou, em geral, superior mas, sob determinadas condições de variação ambiental não muito acentuada, o delineamento aumentado tem precisão semelhante, ocupando uma área menor. Compararam ainda o delineamento aumentado com o látice, que se mostrou, em geral, superior. Sob determinadas condições de variação ambiental não muito acentuada, o delineamento aumentado tem precisão semelhante, ocupando uma área menor.Lin \& Voldeng (1989), trabalhando com ensaios de avaliação de linhagens de soja, encontram, em geral, uma superioridade do ajuste pela testemunha (método 3 ) em relação ao método 1 , baseado no ajuste pelo controle local. 
Vivaldi (1990) simulou condições ambientais de solo, variando a tendência de heterogeneidade dentro dos blocos e, a partir daí, comparou o método de Papadakis, o ajuste por médias móveis sem a retirada dos efeitos de tratamento e o modelo proposto por Wilkinson et al. (1983). Observou que o método de Papadakis forneceu estimativas do erro experimental mais próximas do valor especificado em simulação. Os outros métodos subestimaram o erro experimental em níveis não toleráveis e, quando não o fizeram, apresentaram estimativas superiores ao método de Papadakis. No que diz respeito aos testes de F os métodos foram similares, conflitando, de certa maneira, com os resultados de Wilkinson et al. (1983). O autor observa ainda que o número de parcelas utilizadas para compor a média móvel e o tamanho dos blocos afetam a comparação entre os métodos.

Lin; Binns; Voldeng \& Guillemette(1993) analisaram dados de avaliação de linhagens de soja de várias maneiras, dentre elas a análise como látice, ajuste para controle local e uso da técnica de vizinho mais próximo sugerida por Besag \& Kempton (1987). O ajuste baseado em linhas e colunas não foi superior ao látice, enquanto que se baseando nas observações dos vizinhos mais próximos, a precisão pode ser tão boa ou mesmo superior a do látice.

Deve-se observar que os métodos baseados no ajuste a partir de médias móveis, devem ainda ser bastante estudados quanto a seus aspectos teóricos e resultados conflitantes, como os de Vivaldi (1990) e Wilkinson et al (1983). Devem ser investigados para a certificação quanto a tendenciosidades e eficiências dos diferentes métodos. 
Souza (1997), estudou a viabilidade do uso do delineamento em blocos aumentados, látices e os métodos das médias móveis, testemunha intercalar e de Papadakis, nas etapas iniciais dos programas de melhoramento, onde foram avaliados experimentos independentes de feijoeiro e eucalipto e concluiu que na forma que vem sendo analisado estatisticamente, o delineamento em blocos aumentados não se mostrou apropriado para a estimação de parâmetros genéticos e fenotípicos, devido à baixa precisão das estimativas. Concluiu, também, que os métodos de Papadakis e o das médias móveis, foram eficientes no controle da heterogeneidade dos blocos, sendo essa eficiência similar àquela proporcionada pela análise em látice. 


\section{MATERIAL E MÉTODOS}

Foram utilizados dados gentilmente cedidos pelo programa de melhoramento do feijoeiro do Departamento de Biologia da Universidade Federal de Lavras (UFLA), coordenado pelo Prof. Dr. Magno A. P. Ramalho. O material utilizado para o experimento constituiu-se de 121 progênies $S_{2}$ de um programa de seleção recorrente, cuja população básica foi obtida a partir dos cruzamentos entre 12 linhagens, todas de grãos tipo carioca. Adicionalmente, foram incluídas duas testemunhas, Carioca e EMGOPA-201 - Ouro.

O experimento foi instalado na área experimental do Departamento de Biologia da UFLA, em fevereiro de 1994. Utilizou-se um látice simples $11 \mathrm{x}$ 11. As duas testemunhas foram alocadas, em cada bloco, a intervalos regulares de cinco em cinco parcelas. A parcela foi constituída por duas linhas de dois metros colocando-se 15 sementes por metro linear.

Utilizando-se o mesmo experimento, foi possivel realizar as análises de variância, considerando-se vários procedimentos estatísticos.

Um esquema geral da disposição dos experimentos de feijão pode ser visualizado na Figura 1. 
Repetição I

Bloco I

\begin{tabular}{|l|l|l|l|l|l|l|l|l|l|l|l|l|l|l|l|}
\hline $\mathrm{C}$ & 1 & 2 & 3 & 4 & 5 & $\mathrm{O}$ & $\mathrm{C}$ & 6 & 7 & 8 & 9 & 10 & $\mathrm{O}$ & $\mathrm{C}$ & 11 \\
\hline
\end{tabular}

Bloco XI

\begin{tabular}{|l|l|l|l|l|l|l|l|l|l|l|l|l|l|l|l|}
\hline $\mathrm{O}$ & $\mathrm{C}$ & 112 & 113 & 114 & 115 & 116 & $\mathrm{O}$ & $\mathrm{C}$ & 117 & 119 & 119 & 120 & 121 & $\mathrm{O}$ & $\mathrm{C}$ \\
\hline
\end{tabular}

Repetição II

Bloco I

\begin{tabular}{|l|l|l|l|l|l|l|l|l|l|l|l|l|l|l|}
\hline 1 & 12 & 23 & 34 & 45 & $\mathrm{O}$ & $\mathrm{C}$ & 56 & 67 & 78 & 89 & 100 & $\mathrm{O}$ & $\mathrm{C}$ & 111 \\
\hline
\end{tabular}

Bloco XI

\begin{tabular}{|l|l|l|l|l|l|l|l|l|l|l|l|l|l|l|}
\hline 11 & 22 & 33 & 44 & 55 & $\mathrm{O}$ & $\mathrm{C}$ & 66 & 77 & 88 & 99 & 110 & $\mathrm{O}$ & $\mathrm{C}$ & 121 \\
\hline
\end{tabular}

Figura 1. Disposição na área experimental dos experimentos de feijão, tendo por testemunhas as cultivares Carioca (C) e EMGOPA 201 - Ouro (O) 


\subsection{Látice}

Os dados relativos à produção de grãos (g/parcela) foram submetidos a uma análise de variância segundo o modelo estatístico seguinte, considerando-se o modelo como fixo:

$$
\mathrm{y}_{\mathrm{ijk}}=\mu+\mathrm{p}_{\mathrm{i}}+\mathrm{r}_{\mathrm{j}}+\mathrm{b}_{(\mathrm{j}) \mathrm{k}}+\mathrm{e}_{\mathrm{ijk}}
$$

onde:

$y_{\mathrm{ijk}}$ : valor observado na i-ésima progênie, no k-ésimo bloco, na j-ésima repetição;

$\mu$ : constante;

$\mathrm{p}_{\mathrm{i}}$ : efeito da i-ésima progênie, $\mathrm{i}=1,2, \ldots, 121$;

$r_{j}$ : efeito da j-ésima repetição, $j=1,2$;

$\mathrm{b}_{(\mathrm{j}) \mathrm{k}}$ : efeito do k-ésimo bloco dentro da j-ésima repetição;

$\mathrm{e}_{\mathrm{ijk}}$ : erro experimental, $\mathrm{e}_{\mathrm{ijk}} \cap \operatorname{NID}\left(0, \sigma^{2}\right)$.

A partir da análise de variância foram obtidas as estimativas de herdabilidade $\left(\mathrm{h}^{2}\right.$ - herdabilidade ao nível de médias de progênies) e de seus respectivos intervalos de confiança, segundo Souza (1997). A seguir são apresentadas as expressões para $\hbar^{2}$ e para os limites inferior (LI) e superior (LS) dos intervalos de confiança a $95 \%$.

$$
\overrightarrow{\mathrm{h}}^{2}=\frac{\mathrm{Q}_{1}-\mathrm{Q}_{2}}{\mathrm{Q}_{1}}=\frac{2 \sigma_{\mathrm{p}}^{2}}{\sigma^{2}+2 \sigma_{\mathrm{p}}^{2}}
$$




$$
L I=\left\{1-\left[\left(\frac{Q_{1}}{Q_{2}}\right) F_{1-\alpha / 2 ; z_{3}, g l_{41}}\right]\right\}
$$

onde:

$$
\begin{aligned}
& \mathrm{Q}_{1}=\sigma^{2}+2 \sigma_{\mathrm{p}}^{2} \\
& \mathrm{Q}_{2}=\sigma^{2}
\end{aligned}
$$

$F_{1-\alpha / 2 ; l_{3}, g l_{4}}$ : valor tabelado da tabela de $\mathrm{F}$, com coeficiente de confiança $(1-\alpha / 2) \mathrm{e}$ pelos graus de liberdade $\mathrm{gl}_{3}$ (graus de liberdade para progênies) e $\mathrm{gl}_{4}$ (graus de liberdade para o erro)

$$
\mathrm{LS}=\left\{1-\left[\left(\frac{\mathrm{Q}_{1}}{\mathrm{Q}_{2}}\right) \mathrm{F}_{\alpha / 2 ; \mathrm{gl}_{3}, \mathrm{gl}_{4}}\right]^{-1}\right\}
$$

onde:

$\mathrm{F}_{\alpha / 2 ; \mathrm{Bl}_{3}, \mathrm{~B}_{4}}$ : valor tabelado da tabela de $\mathrm{F}$, com coeficiente de confiança $(\alpha / 2)$ e pelos graus de liberdade $\mathrm{gl}_{3}$ (graus de liberdade para progênies) e $\mathrm{gl}_{4}$ (graus de liberdade para o erro)

\subsection{Blocos Aumentados}

Utilizando-se os dados de cada repetição de experimento, foi possível a realização de análise de variância no delineamento em blocos aumentados, considerando o modelo estatístico fixo:

$$
y_{i j}=\mu+t_{i}+t_{(j) i}+b_{j}+e_{i j}
$$


onde:

$\mathrm{y}_{\mathrm{ij}}$ : valor observado na i-ésima parcela do j-ésimo bloco que recebeu o i'-ésimo tratamento comum ou o i-ésimo tratamento regular dentro do j-ésimo bloco;

$\mu:$ constante;

$t_{i}$ : efeito do i'-ésimo tratamento comum (testemunha), com i' = 1, 2;

$t_{(j) i}$ : efeito do i-ésimo tratamento regular (progênie) dentro do j-ésimo bloco, com i $=1,2, \ldots, 121$;

$b_{j}$ : efeito do j-ésimo bloco, com $\mathrm{j}=1,2, \ldots, 22$;

$e_{i j}$ :erro experimental, $e_{i j} \cap \operatorname{NID}\left(0, \sigma^{2}\right)$;

A análise de variância intrablocos só permite comparações entre tratamentos regulares do mesmo bloco. Assim, para efetuar as comparações entre progênies de blocos diferentes é necessário compor uma nova análise de variância, a partir das médias ajustadas de tratamentos regulares obtidas da análise de variância intrablocos.

Para a realização desta análise com base nas médias ajustadas de tratamentos regulares, Ferreira citado por Barbosa (1996) desenvolveu um testador adequado que foi denominado erro efetivo que é obtido pela seguinte expressão:

$\mathrm{QME}_{\mathrm{c}}=\left[1+\frac{1}{\mathrm{r}+\mathrm{t}-1}+\frac{\mathrm{r}}{\mathrm{t}(\mathrm{r}+\mathrm{t}-1)}+\frac{\mathrm{r} \sum_{\mathrm{k}=1}^{\mathrm{b}} \mathrm{n}_{\mathrm{k}}^{2}}{\mathrm{t}^{2}(\mathrm{r}+\mathrm{t}-1)}+\frac{2 \sum_{\mathrm{k}=1}^{\mathrm{b}} \mathrm{n}_{\mathrm{k}}^{2}}{\operatorname{tn}(\mathrm{r}+\mathrm{t}-1)}+\frac{\mathrm{b} \sum_{\mathrm{k}=1}^{\mathrm{b}} \mathrm{n}_{\mathrm{k}}^{2}}{\mathrm{n}^{2}(\mathrm{r}+\mathrm{t}-1)}\right] \mathrm{QME}_{\mathrm{t}}$

onde: 
QME $E_{\mathrm{e}}$ : quadrado médio do erro efetivo;

$\mathrm{r}$ : número de tratamentos regulares;

t: número de tratamentos comuns;

b: número de blocos;

$\mathrm{n}_{\mathrm{k}}$ : número de tratamentos (regulares + comuns) no bloco $\mathrm{k}$;

$\mathrm{n}$ : número total de parcelas, $\mathrm{n}=\sum_{\mathrm{k}=1}^{\mathrm{b}} \mathrm{n}_{\mathrm{k}}$

$\mathrm{QME}_{\mathrm{t}}$ : quadrado médio do erro da análise intrablocos.

As estimativas de herdabilidade e de seus respectivos intervalos de confiança foram calculados utilizando-se as mesmas expressões apresentadas para o látice.

\subsection{Blocos Casualizados}

As análises de variância foram realizadas a partir do seguinte modelo estatístico fixo:

$$
y_{i j}=\mu+p_{i}+b_{j}+e_{i j}
$$

onde:

$\mathrm{y}_{\mathrm{ij}}$ : valor observado na i-ésima progênie, no j-ésimo bloco;

$\mu$ : constante;

$p_{i}$ : efeito da i-ésima progênie, com $i=1,2, \ldots, 121$;

$b_{\mathrm{j}}$ : efeito do j-ésimo bloco, $\operatorname{com} \mathrm{j}=1,2$; 
$\mathrm{e}_{\mathrm{ij}}$ : erro experimental, $\mathrm{e}_{\mathrm{ij}} \cap\left(0, \sigma^{2}\right)$.

As estimativas de herdabilidade e de seus respectivos intervalos de confiança foram calculados utilizando-se as mesmas expressões apresentadas para o látice.

\subsection{Testemunha Intercalar}

Para esta metodologia, considerou-se a disposição das parcelas no campo. As duas testemunhas, Carioca e ENGOPA 201 - Ouro, foram dispostas juntas a cada cinco parcelas no mesmo bloco. Para a eliminação do efeito genético de cada testemunha, fez-se a média da produção entre elas a cada intervalo de cinco parcelas. A partir destas médias das testemunhas constitui-se um índice ambiental composto pela diferença de produtividade entre estas médias ponderada pela distância da parcela considerada em relação às testemunhas, como recomendado por Baker \& Mackenzie (1967).

Considerar cinco parcelas quaisquer e suas testemunhas:

$$
\text { C } 11233450
$$

O índice ambiental (I) relativo à parcela 1 , por exemplo, será obtido pela seguinte expressão: 


$$
I_{1}=\frac{1}{6}(\mathrm{C}-\mathrm{O})
$$

até a parcela 5 , que será:

$$
\mathrm{I}_{5}=\frac{5}{6}(\mathrm{C}-\mathrm{O})
$$

onde:

C, O: produção média entre as testemunhas Carioca (C) e EMGOPA 201 - Ouro $(\mathrm{O})$;

$1, \ldots, 5$ : parcelas situadas nas posições $1, \ldots, 5$ em relação à $O ;$

$\mathrm{I}_{1}, \ldots ; \mathrm{I}_{5}$ : índices ambientais das parcelas $1, \ldots, 5$.

Utilizando-se este índice ambiental, realizou-se a análise de variância em blocos casualizados com dados de produção ajustados pela testemunha, calculando-se a soma do valor observado de cada parcela com seu respectivo índice ambiental.

\subsection{Método das Médias Móveis}

Os valores observados em cada parcela $(i, j)$ foram corrigidos pela média dos valores observados de seis parcelas vizinhas, três à esquerda e três à direita. Para casos de parcelas nas extremidades, utilizaram-se os valores observados nas parcelas imediatamente à frente ou atrás delas. A média móvel de 
cada parcela foi usada como covariável, e realizou-se uma análise de covariância em blocos casualizados, considerando-se o seguinte modelo estatístico:

$$
y_{i j}=\mu+p_{i}+b_{j}+\beta I_{i j}+e_{i j}
$$

onde:

$\mathrm{y}_{\mathrm{ij}}, \mu, \mathrm{p}_{\mathrm{i}}, \mathrm{b}_{\mathrm{j}}$ e $\mathrm{e}_{\mathrm{ij}}$ têm o mesmo significado vistos anteriormente;

$\beta$ : coeficiente de regressão linear da variável produção de grãos sobre a covariável índice ambiental;

$\mathrm{I}_{\mathrm{ij}}$ : índice ambiental da parcela que recebeu a i-ésima progênie no j-ésimo bloco.

\subsection{Discussão dos Métodos}

Os métodos antes descritos foram comparados no tocante às suas respectivas estimativas de coeficiente de variação e de herdabilidade. Foi também calculado o coeficiente de correlação de Spearman entre as médias ajustadas de progênies nos vários modelos de análise de variância e de covariância, para verificar a concordância quanto à classificação das progênies. 


\section{RESULTADOS E DISCUSSÃO}

Programas de melhoramento normalmente são desenvolvidos considerando-se a avaliação de um grande número de progênies, principalmente nas etapas iniciais do programa, visando explorar com maior intensidade a variabilidade genética disponivel.

Diante disso, os melhoristas têm buscado alternativas de procedimentos estatísticos que contornem o problema de escolha do delineamento experimental, procurando aquele que possibilite a avaliação de todas as progênies com a máxima precisão dentro dos recursos disponíveis quanto ao material genético, área experimental e mão de obra.

Os resumos das análises de variância e as médias para a produção de grãos (g/parcela) para todos os procedimentos de análise estatística estudadas são apresentados na Tabela 3 . 
Tabela 3. Resumo das análises de variância da produção de grãos (g/parcela) do feijoeiro e médias gerais.

\begin{tabular}{lllll}
\hline Delineamentos & GL Erro & QMErro & F para Progênies & Média (g/parcela) \\
\hline Látice & 100 & 6630,8 & $1,55^{*}$ & 227,2 \\
Bl. Aumentados 1 & 22 & 8162,6 & $1,38^{\text {n.s. }}$ & 233,0 \\
Bl. Aumentados 2 & 22 & 4759,5 & $2,54^{* *}$ & 242,8 \\
DBC & 120 & 7024,1 & $1,43^{*}$ & 227,2 \\
Test. Intercalar & 120 & 9581,2 & $1,44^{*}$ & 226,3 \\
Média Móvel & 119 & 5296,4 & $1,68^{* *}$ & 227,2 \\
\hline
\end{tabular}

onde: ${ }^{*} \mathrm{e}^{* *}$ teste $\mathrm{F}$ significativo a $5 \%$ e $1 \%$, respectivamente.

DBC: Delineamento em Blocos Casualizados

Observa-se que as estimativas dos quadrados médios do erro (QMErro) variam entre os diferentes procedimentos de análise de variância estudados. Destaca-se a estimativa do QMErro obtida na análise de variância em blocos casualizados ajustado pela testemunha intercalar que foi de magnitude superior em relação às estimativas nos demais procedimentos. Embora ocorram discrepâncias entre os valores das estimativas do QMErro, estas podem ser consideradas homogêneas, utilizando-se o critério proposto por Pimentel Gomes (1987), que diz que o quociente entre o maior e o menor QMErro deve ser inferior a 7 .

$\mathrm{O}$ teste $\mathrm{F}$ foi significativo para o efeito de progênies para todos os procedimentos de análise de variância, à exceção do delineamento em blocos aumentados 1, mostrando (Tabela 3 ) que foi possível detectar diferenças entre as progênies. 
Deve ser salientado que o número de graus de liberdade do Erro no delineamento em blocos aumentados é bem inferior às demais estratégias (Tabela 3) em função da restrição no número de testemunhas utilizadas. É oportuno comentar que o número de graus de liberdade do QMErro aumentará à medida que se aumente o número de tratamentos comuns. Porém, isso é questionável, pois, dependerá do número de tratamentos regulares e do tamanho do bloco.

A estimativa da precisão é o coeficiente de variação (CV). Pelos resultados apresentados na Tabela 6 , verifica-se que as estimativas do CV foram elevadas para todos os procedimentos de análise estatística, sendo que elas variam de $28,41 \%$ para a produção de grãos no delineamento em blocos aumentados 2 a $43,25 \%$ no delineamento em blocos casualizados ajustado pela testemunha intercalar.

Tabela 4. Coeficientes de Variação (CV \%) da produção de grão (g/parcela) do feijoeiro em todos os procedimentos estatísticos avaliados

\begin{tabular}{ll}
\hline Delinemantos & CV (\%) \\
\hline Látice & 35,83 \\
Blocos Aumentados 1 & 38,78 \\
Blocos Aumentados 2 & 28,41 \\
DBC & 36,88 \\
Testemunha Intercalar & 43,25 \\
Média Móvel & 32,03 \\
\hline
\end{tabular}

Como pode-se observar, estes valores são altos (sendo considerados ideais CV entre $0-20 \%$ ), indicando a baixa precisão destes experimentos. O CV 
destes experimentos foi de valores maiores que os normalmente encontrados para a cultura do feijoeiro.

$\mathrm{Na}$ Tabela 5 são apresentadas as estimativas de herdabilidade entre médias de progênies e seus respectivos intervalos de confiança para produção de grãos para os procedimentos de análise de variância estudados.

Tabela 5. Estimativas das herdabilidades e seus respectivos intervalos de confiança $(1-\alpha=0,95)$ da produção de grãos de feijão para todos os procedimentos estatísticos avaliados.

\begin{tabular}{llll}
\hline Delineamentos & $\mathrm{h}^{2}(\%)$ & $\mathrm{LI}$ & $\mathrm{LS}$ \\
\hline Látice & 35,53 & 5,68 & 55,65 \\
Bl Aumentados 1 & 27,31 & $-46,09$ & 58,69 \\
Bl Aumentados 2 & 60,58 & 20,76 & 77,60 \\
DBC & 30,12 & 5,52 & 51,22 \\
Testemunha Intercalar & 30,52 & 6,08 & 51,51 \\
Média Móvel & 40,64 & 14,89 & 58,60 \\
\hline
\end{tabular}

Percebe-se que as estimativas de $\mathrm{h}^{2}$ variam amplamente entre os procedimentos estatísticos de análise de variância. Nota-se que a amplitude entre as estimativas dos limites inferior e superior do intervalo de confiança de $h^{2}$ foi grande. Estes resultados são, provavelmente, o reflexo da baixa precisão do experimento.

Os coeficientes de correlação de Spearman entre as médias estimadas no látice e as médias estimadas nos demais procedimentos de análise de variância estudadas estão apresentadas na Tabela 6. 
Tabela 6. Coeficientes de correlação de Spearman entre as médias estimadas no látice e nos demais procedimentos de análise de variância da produção de grãos do feijoeiro.

\begin{tabular}{ll}
\hline Delineamentos & Coeficiente de Correlação de Spearman \\
\hline Blocos Aumentados & 0,5440 \\
DBC & 0,9792 \\
Testemunha Intercalar & 0,9807 \\
Média Móvel & 0,9221 \\
\hline
\end{tabular}

Estes resultados mostram que não houve grandes diferenças entre a classificação das médias dos tratamentos obtidas no látice $\mathrm{e}$ nos demais procedimentos, à exceção de delineamento em blocos aumentados.

Os resultados obtidos reforçam a idéia que o delineamento em blocos aumentados é uma alternativa viável, pois os demais procedimentos são semelhantes ao látice, para a avaliação de um grande número de progênies em etapas iniciais dos programas de melhoramento.

Para maior eficiência do látice alguns aspectos devem ser considerados, como a utilização de testemunhas adequadas que representem bem a variação "ambiental" da população segregante em estudo, procurando-se dentro do possível, utilizar alguns genótipos que estejam sendo avaliados, Bearzoti (1994).

Outro aspecto a ser considerado, é em relação às estimativas dos parâmetros genéticos obtidos pelo delinemanto em blocos aumentados. Tomandose como exemplo a estimativa para a herdabilidade, o método mostrou-se 
deficiente, apresentando estimativas de baixa precisão. Bearzoti (1994) cita que uma forma de melhorar a qualidade de suas estimativas seria a de, à semelhança dos blocos incompletos, recuperar a informação interblocos.

Portanto, o delineamento em blocos aumentados pode ser útil nas etapas iniciais de um programa de melhoramento de plantas, por permitir a avaliação de um grande número de progênies, utilizando menor área e menor quantidade de insumos, o que acarreta em maior facilidade de planejamento e condução do experimento. A menor precisão das estimativas, não chega a comprometer a sua utilidade, nas fases iniciais de programas de melhoramento de plantas.

É importante salientar que os blocos aumentados não são a única opção dos melhoristas. Os métodos de análise espacial têm recebido grande destaque, nos últimos anos. Inúmeras comparações são relatadas na literatura e, em praticamente todas elas, há vantagem no seu emprego, desde que o experimento tenha sido conduzido em blocos casualizados, com repetições.

Torna-se necessário realçar que com os recursos computacionais atuais, outras técnicas de análise de vizinhança devam ser estudadas, como os métodos de Wilkinson et al (1983), de Green et al (1985), de ajuste local (Anoeskenko, 1996), que apresentam técnicas mais refinadas na detecção da heterogeneidade espacial. 


\section{CONCLUSÕES}

Com os resultados obtidos no presente trabalho, pode-se concluir que:

1. Este trabalho reforça e idéia de que o emprego do delineamento em blocos aumentados é viável para a seleção de progênies nas etapas iniciais de programas de melhoramento de plantas, devido a menor quantidade de área utilizada e menor consumo de insumos.

2. O delineamento em blocos aumentados não se mostrou apropriado para a estimação de parâmetros genéticos, devido à baixa precisão das estimativas

3. O método das médias móveis foi eficiente no controle da heterogeneidade dos blocos, sendo esta eficiência semelhante àquela proporcionada pelo látice. 


\section{REFERÊNCIAS BIBLIOGRÁFICAS}

ANOSHENKO, B.Y. Local adjustment method for field experiments. 1. The method and this its examination by computer simulation. Euphytica, Wageningen, v.90, n.2, p.137-148, 1996.

ATKINSON, A.C. The use of residuals as a concomitant variabloe. Biometrika, v.56, n.1, p.33-41, 1969.

BAKER, R.J. ; McKENZIE, R.J.H. Use control plots in yeld trials. Crop Science, v.7, p.335-337, 1967.

BARTLET, M.S. The approximate recovery of information from field experiments with large blocks. Journal of Agricultural Science, v.28, p.335-337, 1938.

BARTLET, M.S. Nearest neighbour models in the analysis of field experiments. Journal of the Royal Statistical Society: Series B, v.40, n.2, p.147-174, 1978. 
BEARZOTI, E. Comparação entre métodos estatísticos na avaliação de clones de batata em um programa de melhoramento. Dissertação - (mestrado) Escola Superior de Agricultura de Lavras. Lavras, 1994. 128p.

BASSO, L.C. Estimação de componentes de variância. Os métodos de Henderson. Dissertação - (Mestrado) - Instituto de Matemática e Estatística Universidade de São Paulo, 71p. 1981.

BESAG, J. ; KEMPTON, R. Statistical analysis of field experiments using neighbouring plots. Biometrics, v.42, p.231-251, 1986.

BESAG, J. ; KEMPTON, R. Statistical analysis of field experiments using neighbouring plots. Biometrics, v.42, p.231-251, 1986.

BOS, I. ; hENNINK, S. A comparison of several procedures for mass selection in winter rye. II. what are the merits of adjusting phenottypic values? Euphytica, v.52, p.57-64, 1991.

BOSE, R.C. \& NAIR, K.R. Partially balanced incomplete block designs. Sankhya, v.4, p. 337-372, 1939.

BOX, G.E.P. \& JENKINS, G.M. Time series analysis: forecasting and control. San Francisco: Holden - Day, 1976.

CECON, P.R. Alternativas de análise de experimentos em látice e aplicações no melhoramento vegetal. Tese - (Doutorado) - Escola Superior de Agricultura "Luiz de Queiroz" - Universidade de São Paulo. 1992 
CHAVES, L.J. Tamanho da parcela para a seleção de progênies de milho Zea mays L.. Tese - (Doutorado) - Escola Superior de Agricultura "Luiz de Queiroz"' - Universidade de São Paulo. Piracicaba, 1985. 148p

COCHRAN, W.G. Analysis of covariance: its nature and uses. Biometrics, v.13, p.261-281, 1957.

COCHRAN, W.G. ; COX, G.M. Experimental Designs. 2. ed. New York: John Wiley \& Sons, 1966. 611p.

DIERS, B.W.; VOSS, B.K.; FEHR, W.R. Moving mean analysis of field tests for iron efficiency of soybean. Crop Science, v.31, p.54-56, 1991.

ES, H.M. \& ES, C.L. Spatial nature of randomization and its effect on the outcome of field experiments. Agronomy Journal, v.85, p.420-428, 1993.

FEDERER, W.T. Experimental Designs: theory and application. New York: Macmillan, 1955. 590p.

FEDERER, W.T. Augmented (or hoonuiaku) designs. Hawaiian Planters Record, v.55, p.191-208, 1956.

FEDERER, W.T.; NAIR, R.C. \& RAGHAVARAO, D. Some augmented rowcolumn designs. Biometrics, v.31, p.373-386, jun. 1957. 
FEDERER, W.T.; RAGHAVARAO, D.R. On augmented designs. Biometrics, v.13, p.373-386, 1957.

FINNEY, D.J. Stratification, balance and covariance. Biometrics, v.13, p.373$386,1957$.

FISHER, S. Séries univariantes de tempo. Metodologia de Box \& Jenkins. Porto Alegre. 1982. Dissertação - (Mestrado) - FEE.

GODOI, R.E.Z. Avaliação de progênies de milho (Zea mays L.) utilizando testemunha intercalar. Dissertação - (Mestrado) - Escola Superior de Agricultura "Luiz de Queiroz" - Universidade de São Paulo. Piracicaba: 1991

GREEN, P.J.; JENNISON, C.; SEHEULT, A.H. Analysis of field experiments by least squares smoothing. Journal of the Royal Statistical Society, London,47: 299 - 315, 1985.

HANNAN, E.J. Time series analysis. Londres: Chapman and Hall, 1975. 152p.

HARHBARGER, B. Triple rectangular lattices. Biometrics, v.5, p.1-13, 1949.

HENDERSON, C.R. Estimation of variances and covariance components. Biometrics, v.9, n.2, p.226-252. 1953

JENSEN, N.F. ; FEDERER, W.T. Adjacent row competion in wheat. Crop Science, v.4, p.641-645, 1964. 
JOHNSON, I.J. \& MURPHY, H.C. Lattice and lattice square designs with oat uniformity data and in variety trials. Journal of the American Society of Agronomy, v.35, p.291-305, 1943.

KEMPTON, R.A. Adjustament for competition between varieties in plant breeding trials. Journal of Agricultural Science, v.98, p.599-611, 1982.

KEMPTON, R.A. ; HOWES, C.W. The use of neigbouring plot values in the analysis of variety trials. Applied Statistics, v.30, n.1, p.59-70, 1981.

KSHIRSAGAR, A.M. A Course in linear models. New York: Marcel Dekker, 1983. 422p.

LESSMAN, K.J. ; ATKINS, R.E. Optimum plot size and relative efficiency of lattice designs for grain sorghum yield tests. Crop Science, v.3, p.477-481, 1963.

LIN, C.S.; BINNS, M.R.; VOLDENG, H.D. ; GUILLEMETTE Performance of randomized block designs in field experiments. Agronomy Journal, v.85, p.168-171, 1993.

LIN, C.S. ; POUSHINSKY, G. A modified augmented design for an early stage of plant section involving a large number of test lines without replication. Biometrics, v.39, p.553-561, set. 1983.

LIN, C.S.; POUSHINSKY, G. ; JUI, P.Y. Simulation study of tree adjustment methods for the modified augmented design and comparison with the 
balanced lattice square design. Journal of Agricultural Science, v.100, p.527-534, 1983.

LIN, C.S.; VOLDENG, H.D. Efficiency of type 2 modified augmented designs in soybean variety trials. Agronomy Journal, v.81, p.512-517, 1989.

LOCKWOOD, G. Adjustment by neighbouring plots in progeny trials with cocoa. Experimental Agriculture, v.16, p.81-89, 1980.

MAK, C.; HARVEY, B.L. ; BERDAHL, J.D. An evaluation of control plots and moving means for error control in bartley nurseries. Crop Science, v.18, p.870-873, 1978.

McCLELLAND, C.K. New methods with check plots. Journal of the American Society of Agronomy, v.18, p.566-575, 1926.

MIRANDA FILHO, J.B. Princípios de experimentação e análise estatística. In: PATERNIANI, E. (Coord.) Melhoramento e produção de milho na Brasil. Campinas: Fundação Cargill. 1987

NOGUEIRA, M.C.S. Análise conjunta para experimentos em blocos casualizados completos aumentados. Dissertação - (Mestrado) - Escola Superior de Agricultura "Luiz de Queiroz"- Universidade de São Paulo, 1976.

ORD, K. Estimation methods for models of spatial interaction. Journal of the American Statistical Association, v.70, n.349, p.120-126, 1975. 
PAGE, E.S. A note on gerating random permutations. Appied Statistics, v.16, p.273-274, 1967.

PAPADAKIS, J.S. Méthod Statistique pou des experiences sur champ. BULL. Inst. Amelor. Plantes à Salonique, 23, 1937.

PEARCE, S.C. The control of enviromental variation in some West Indian maize experiments. Tropical Agriculture, v.55, n.2, p.97, 1978.

PEARCE, S.C. ; MOORE, C.S. Reduction of experimental error in perennial crops, using adjustment by neighbouring plots. Experimental Agriculture, v.12, p.267-272, 1976.

PIMENTEL GOMES, P. Curso de Estatística Experimental. 12.ed. Piracicaba: Nobel, 1987. 467p.

RICHEY, F.D. Adjusting yelds to their regression on a moving average, as a means of correcting for soil heterogeneity. Journal of Agricultural Reserch, v.27, p.79-90, 1924.

ROSIELLE, A.A. Comparison of lattice designs, check plots, and moving means in wheat beeding trials. Euphytica, v.29, p.129-133, 1980.

SCHAALJE, G.B.; LYNCH, D.R. ; KOZUB, G.C. Field evaluation of a modified augmented design for early stage selection involving a large number of test lines without replication. Potato Research, v.30, p.35-45, 1987. 
SCUTZ, W.M. ; COCKERHAM, C.C. The effect of field blocking on gain from selection. Biometrics, v.22, p.843-863, 1966.

SEARLE, S.R. Linear models for umbalanced data. New York: John Wiley \& Sons, $1987.536 \mathrm{p}$.

SHORTER, R. \& BUTLER, D. Effect of moving mean covariance adjuntments on error and genetic variance estimates and selection of superior lines in peanuts (Arachis hypogaea L.) Euphytica, v.35, p.185-192, 1986.

SMITH, H.F. An empirical law describing heterogeity in the yelds of agricultural crops. Journal of Agricultural Science, v.28, p.1-23, 1938.

SOUZA, E.A. Alternativas experimentais na avaliação de progênies em programas de melhoramento genético vegetal. Tese - (Doutorado) - Escola Superior de Agricultura "Luiz de Queiroz" - Universidade de São Paulo, 1997. 122p.

STEEL, R.G.D. ; TORRIE, J.H. Principles and procedures of statistics. 2 ed. New York: McGraw-Hill, 1980.633p.

STROUP, W.W. ; MULITZE, D.K. Nearest neighbour adjusted best linear unbised prediction. The American Statistician, v.45, n.3, p.194-200, 1991.

TOLLEDO, G.L. ; OVALLE, I.I. Estatística básica. 2 ed. Atlas, 1985. 459p.

TORANZOS, F.I. Estadística. 2. ed. Kapelusz, 1966. 377p. 
TOWNLEY-SMITH, T.F. ; HURT, E.A. Use of moving means in grass yield trials. Canadian Journal of Plant Science, v.55, p.587-604, 1973.

VENCOVSKY, R. ; BARRIGA, P. Genética biométrica no fitomelhoramento. Ribeirão Preto: Revista Brasileira de Genética, 1992. 496p.

VIVALDI, L.J. Comparação entre métodos de análise espacial de experimentos de campo. Pesquisa Agropecuária Brasileira, v.25, n.1, p. 77-84, jan. 1990

WEINBAUN, S.A.; SHAW, D.V.; AZARI, R. ; MURAOKA, T.T. Mass selection of walnut rootstocks using response surface methods to correct for environmental trends. Euphytica, v.46, p.227-235, 1990.

WIANCKO, A.T. Use and management of check plots in soil fertility investigations. Journal of the American Society of Agronomy, v.6, p.122$124,1914$.

WILLIAMS, E.R. A neighbour model for field experiments. Biometrika, v.73, n.2, p.279-287, 1986.

WILLIAMS, R.M. Experimental designs for serially correlated observations. Biometrika, v.73, n.2, p.151-167, 1952.

WILKINSON, G.N. ; ECKERT, S.R. ; HANCOCK, T.W. \& MAYO, O. Nearest neighbour (NN) analysis of field experiments. Jounal of the Royal Statistical Society: Series B, v.45, n.2, p.151-211, 1983. 
YATES, F. A new method of arranging variety trials involving a large number of varieties. Journal of Agricultural Science, v.26, p. 424-455, 1936.

YATES, F. The recovery of inter-block information in variety trials arrranged in tree dimensional lattices. Annals of Eugenics, v.9, p.136-156, 1939

ZELEN, M. The analysis of covariance for incomplete block designs. Biometrics, v.13, p.309-332, 1957.

ZUBER, M.S. Relative efficiency of incomplete block designs using corn uniformity trial data. Journal of the American Society of Agronomy, New York, 34: 30-47, 1942. 